\title{
The Development Of The Merchant Advance Industry As An Example Of Innovation In The Financial Markets
}

Dean Drysdale, Kwantlen Polytechnic University, Canada David Gens, University of British Columbia, Canada

\begin{abstract}
The capital markets, like all areas of business, evolve over time. This evolution is often made possible by the application of technology. In particular, stock and bond markets, as well as options, commodities and derivatives markets, have all undergone enormous and rapid transformations due to the application of technology (Gurbaxani \& Whang, 1991; Carlsson \& Stankiewicz, 1995).

These transformations, because of economies of scale, have benefited large businesses more than small businesses. This article 1) outlines the development of a new form of financing for small business that has become possible as a result of technological innovation, 2) describes why it has advantages in some circumstances over existing forms of financing, and 3) examines why the existence of this form of financing may have positive effects in terms of job creation.
\end{abstract}

Keywords: Merchant Advance; Innovation in Capital Markets

\section{THE IMPORTANCE OF CAPITAL TO BUSINESS GROWTH}

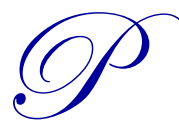

roper capitalization is almost always a challenge for a growing enterprise (Van Auken \& Doran, 1989). Whether it is funding for accounts receivable, inventory, the purchase of equipment, advertising, or simply payroll expenses, the availability of cash can often determine the success or failure of a growing business. However, while this applies to all businesses, big or small, the capital markets function very differently depending on the size of a business and its capital requirements (Korajczyk \& Levy, 2003).

The primary reason why the capital markets function differently for large companies than for small ones is the cost of entering into a transaction (Faulkender, Flannery, Hankins, \& Smith, 2012). These costs include the time, effort, and professional fees incurred during the due diligence phase of the deal, as well as the costs of actually structuring and ultimately closing on the transaction. Finally, after the transaction is consummated, the providers of capital have to pay the costs of monitoring their investment.

While transaction costs increase with the size of a deal, they do not increase proportionately. This is because there exists a low-end 'threshold' cost for even the smallest contractual agreement (Nooteboom, 1993). Put differently, the transaction costs for a small transaction are going to be higher than for a large transaction on a percentage basis since the costs of any given transaction cannot decrease below a certain minimum. One result of this economy of scale is that as a deal increases in size the providers of capital can provide more sophisticated and creative solutions that are more tailored to the specific circumstances faced by the business that is raising capital. As expected, the proportional costs of such customization decrease as the magnitude of the transaction increases, thus allowing time- and resource-intensive capitalization solutions to become financially viable in a way that is not possible with smaller deals. 
Two examples highlight the different capitalization processes of large and small businesses nicely.

\section{THE LARGE COMPANY EXAMPLE}

Let's say a large public company in the telecommunications sector wants to raise $\$ 1.5$ billion to finance the construction of a new data network.

From a due diligence perspective, the company is audited by a Big Four auditor, reports quarterly to the public, and releases news to the press to keep the public up-to-date on material events. Wall Street analysts study the company's actions and write reports about the business and its industry. An elected board hires managers, oversees the business, and accepts the responsibility of fiduciary duty to shareholders. Institutional investors such as pension funds and mutual funds hire well-educated financial analysts to study all of this information, build financial models, write reports, and ultimately decide whether to invest in this business.

Generally, investors are able to: a) trust the numbers being presented, b) study a wealth of information regarding the company's history, c) take steps to understand a company's industry and its position and strategy within it, d) have some faith that the monitoring of their investment is being done by a professional board of directors, and e) have the human capacity available to actually investigate and analyze all of this information.

While these are generalizations and there are certainly exceptions (particularly with respect to boards of directors and their potential misalignment of interests with shareholders), these dynamics serve to shore up investor confidence when investing in a public company and therefore decrease its cost of capital.

With respect to the structuring and ultimate execution of the $\$ 1.5$ billion offering, the company hires an investment bank that carefully studies capital market conditions present at the time. By working with the executives of the company and liaising with the capital markets, the investment bankers figure out the details of the offering, including the type of securities that will be offered, whether that is common or preferred shares, bonds, debentures or other more exotic instruments.

It is interesting to note that the items that will need to be collected during due diligence will be the same regardless of whether the company decides to issue equity or debt. This allows large companies to begin the capital raising process and only later decide what type of securities to issue depending on the appetites of the capital markets and the requirements of the business.

For our example, we will assume the company decides to issue a bond. The advisors will decide what legal covenants will have to be in place throughout the duration of the debt, any special take-out or change-of-control features, and of course its interest rate, maturity date, and payment schedules. Securities lawyers will work long hours to conclude these legal agreements and traders on the trading floor of the investment bank will dial their institutional clients to place the debt and close the transaction on the offering date.

There will be a legion of well paid professionals involved in this process - accountants, lawyers, investment bankers and other experts - who will orchestrate this movement of capital, allowing this example company to fund its growth. All of this is made possible by the sheer size of the transaction, a whopping $\$ 1.5$ billion.

The transaction costs for the issuance, which would go to pay the salaries, bonuses, and commission payments of all of the professionals involved, would be in the millions of dollars. But despite their size in absolute dollars, they will not account for a material percentage of the overall deal, probably below $1 \%$ of the total. The size of the deal will allow the large firm to obtain a high level of sophistication and customization of the transaction which will allow the company to get the right solution from a funding perspective at a reasonable cost.

Now, let's take a look at the other end of the spectrum using a real life example. 


\section{THE SMALL COMPANY EXAMPLE}

A young man buys the Canadian master franchise license for a Mexican restaurant from its U.S.-based parent company. He reaches into his own pocket and funds the construction of his first restaurant. The result is a success - long line-ups, strong sales, and a great initial response to the brand and dining experience. So, what next? Logically it makes sense to expand. He knows his business would be a success in other parts of his city. He knows that the fast-casual dining sector (Mexican food in particular) is the fastest growing segment of the foodservice industry. He also knows that other restaurants are gaining traction. He needs to move quickly to obtain a first mover advantage. However, he does not have additional personal funds available for this expansion. He needs to raise capital to execute on his plan.

The small entrepreneur has fewer options than the large company. Like the large company, he can raise equity or raise debt. But his options are more limited in terms of how he does it.

As is the case with many small businesses, the business owner could attempt to raise equity privately (Berger \& Udell, 1998) - say, through his existing network of fellow restaurateurs and local businesspeople that are familiar with his business. Those investors will be primarily interested in the prospects of his business in terms of demand for his product or service.

Investors will see this investment as inherently risky and the business owner would likely have to sell a substantial piece of his company in order to raise equity, in this case, something approaching half of his business. Given the relative informational opacity of small businesses such as the one described here and the limited financial resources of the parties involved, the due diligence would be done privately between the two individuals with some help from a lawyer. There would be no auditors, no investment bankers, and no investment analysts. This would place a time burden on the entrepreneur, who at this time is also trying to run his business.

It is significant to note that this equity raise is highly dependent on the personal network of the entrepreneur, which may or may not contain people who are in a position to participate in this type of investment. While a few third party actors do exist that specialize in bringing together investors and small businesses in need of equity capital, these are relatively scarce and few businesses are funded in this manner (Berger \& Udell, 1998).

Even though professionals are not taking much of the burden off the shoulders of the entrepreneur, professional fees for accountants and lawyers could easily reach $25 \%$ of the value of the transaction. This is not to say that the accountants and lawyers are overcharging, only that the transaction costs, on a small transaction, can be large on a percentage basis. It is important to note that these fees will be borne by the entrepreneur.

If the entrepreneur instead decided to raise debt, he would likely approach his own bank. Again, given the informational opacity of small businesses, the small business advisor at the local branch would generally ask the entrepreneur to provide three years of accountant-prepared financial statements. However, as the business in question has simply not been operational for that length of time, the business owner ultimately will not be able to provide such statements. The banker would also ask the business owner for a personal net worth statement. If the entrepreneur lacks collateral to secure the loan, a loan offer is unlikely.

At this point, the entrepreneur's business plan, the trajectory of his industry, and the capital investment plan are likely not even considered by the banker. There is no customization in the structure of the investment, the deal simply has to fit the bank's pre-existing business model that is highly dependent on collateral and historical cash flow - the very things that the start-up entrepreneur lacks. If the loan is offered, it will be structured in the same way as the other loans in the bank's portfolio.

Clearly, then, raising debt is very difficult and raising equity is very expensive. Compounding such problems, the equity investors and the bankers involved in this process, unlike for the large firm, will be looking for different types of information. In particular, the equity investors will generally be more interested in forward looking projections while the bankers will tend to more heavily scrutinize collateral and historical financial information. This places additional costs on the entrepreneur, both informational as well as financial. 
As we can see, when the small business tries to raise capital there are fewer professionals involved in the process and, as a result, there is also much less sophistication and customization. This tends to result in fewer alternative solutions and a much higher cost of capital (if any capital is available at all). The fundamental issue is that the relatively small size of the financing simply does not allow for it, and there is no solution to this problem. Capital injections into small businesses must be kept simple and cost-effective in order to justify any sort of transaction at all. We will call this the 'size challenge'.

\section{THE IMPORTANCE OF THE SMALL BUSINESS SECTOR}

While this 'size challenge' affects mainly small business owners, it is important to understand the vital role the small business plays in the Canadian economy. Small to medium sized businesses generate approximately $45 \%$ of Canada's GDP (Oliver Wyman, 2010; Industry Canada, 2011), employ close to 60\% of the Canadian work-force and create the vast majority of new jobs. Small businesses are the lifeblood of our economy and their access to capital is crucial to its growth, yet, as seen above, financing at a reasonable cost is often not available to them. Indeed, surveys of Canadian small business owners have repeatedly shown that, by-and-large, these entrepreneurs tap financing troubles as a major impediment to their success (e.g. Gill \& Biger, 2012).

Additional forms of finance to small business, that keep transaction costs to a minimum, could have positive effects on job creation.

\section{AN EXAMPLE OF A TECHNOLOGY BASED PRODUCT DEVELOPED TO ADDRESS THIS NEED}

One such alternative is a "Merchant Advance" which is a technology enabled financing product which is based on credit card cash flow. The business looking to raise capital is qualified based on its sales that are electronically processed with a credit or debit card. The Merchant Advance involves the purchase of a certain amount of future sales revenues at a discount.

To give an example of a typical Merchant Advance deal, the funder might give $\$ 60,000$ in capital to the entrepreneur in exchange for $\$ 80,000$ of the firm's future sales revenue. The entrepreneur would then pay a fixed percentage of his total debit and credit card sales, say $8 \%$, until the $\$ 80,000$ is repaid.

This is somewhat similar to traditional accounts-receivable factoring arrangements, in which the business sells a portion of its receivables from past sales. In this case, however, the business sells a portion of its anticipated future sales.

This form of finance is only possible through recent advances in technology. The payback is automatic and occurs each day as debit/credit card sales are made. A percentage of the total receipts from each day's sales are simply "swept" into the funders account. This lowers the cost of collection compared to what would be the case if collections were done through the more traditional process of payment by cheque.

The Merchant Advance has a couple of advantages over more traditional forms of finance. Because the Merchant Advance underwriting model is based on a few simple checks to evaluate a business's solvency and recent (generally one year's) sales history as opposed to its collateral position, many businesses qualify that would be rejected for traditional bank financing. Because these funds will be paid back, the owner will not have to relinquish any ownership of his business as he would have had to do if he had elected to raise equity.

While this may appear to be an expensive source of funds if the discount on the Merchant Advance is compared only to the interest costs on a bank loan, this discrepancy is reduced or eliminated once fees are taken into account. There are typically no fees charged for a Merchant Advance. Fees, for a traditional bank loan of the size contemplated in the preceding paragraph could easily be $\$ 10,000$. Fees on an equity investment of that size would likely be closer to $\$ 20,000$. Once fees are considered, the cost of a Merchant Advance is comparable to these other alternatives. 
Because these fees, on traditional sources of financing are fairly fixed, this means that the Merchant Advance becomes even more economical for smaller sums.

Ultimately, this type of innovation is not unique in the rapidly evolving financial services industry. What is unique, though, is that it benefits small rather than large businesses.

\section{HISTORY OF THE MERCHANT ADVANCE INDUSTRY}

The Merchant Advance business began in the United States in the late 1990s with AdvanceMe Inc. based in Kennesaw, Georgia. Over the years, however, a number of additional companies have entered the US market. In 2002, for example, David Goldin founded AmeriMerchant LLC, headquartered in New York, New York.

With the entrance of these additional actors into the American market, AdvanceMe filed a lawsuit against several of the new entrants for infringing upon a patent it had filed (Johnson, 2005). Specifically, the patent related to a computerized method for securing an obligation against future credit card receivables. However, on August 14th, 2007 a US District Court, Eastern District of Texas ruled against AdvanceMe Inc., declaring the patent invalid due to prior art (transactions similar to Merchant Advances had been done before) and the obvious and anticipated nature of the patent (any party could have thought of it) (AdvanceMe Inc. v. RAPIDPAY, LLC, 2007). This opened the floodgates for new entrants in the US and, as a result, the US market is now quite developed with many significant players.

Despite the emergence of the Merchant Advance industry in the United States more than a decade ago, the industry is a relative newcomer to Canada, emerging only in 2006. However, a number of businesses have entered the Merchant Advance industry, including the Quebec-based AdvanceIt Financial and the British Columbia-based Merchant Advance Capital which operates in Ontario, the Maritimes and Western Canada.

David Gens, President and CEO of Merchant Advance Capital, one of the industry pioneers, says "I just want every small business owner to know that this is an option for them. As with any financing and capital investment plan, there needs to be an opportunity that is being capitalized and its risks need to be carefully evaluated by the business owner. But if an opportunity arises for a business, we believe that a Merchant Advance is a tremendously effective tool in an incredibly under-served part of the capital markets."

\section{PUBLIC POLICY CONSIDERATIONS}

As seen through such government initiatives as the Canada Small Business Financing (CSBF) Program, the Canadian government has continued to recognize the importance of small business to the Canadian economy and the need to reduce barriers to access for critical funding for young and small companies. Between 2004 and 2009 alone, this program supported approximately $\$ 5.1$ billion in loans to more than 40,000 small businesses in Canada (Industry Canada, 2010). However, despite the program's stated intention of facilitating access to funding for small and developing businesses that would likely fail to otherwise obtain a source of funding, the use of the CSBF program dropped more than $25 \%$ between 2004 and 2009. While a range of factors are at play in this decrease in use, the sheer administrative burden of the program was identified as one of the major obstacles to participation (Industry Canada, 2010). In particular, CSBF Program borrowers "faced more stringent credit application requirements than other SME [small and medium-sized enterprises] borrowers in terms of documents requested and collateral required as security" (Carrington, 2009). It would seem, then, that new financing techniques that put capital into the hands of entrepreneurs quickly, and with a minimum of costs, will have positive economic effects. In particular, the high survival rates of Canadian small and medium-sized businesses at both the one- and five-year mark are clear signs that new and cost-effective financing techniques have real and material payoffs to be realized for all Canadians without undue risk of loss of investment (Fisher \& Reuber, 2010).

As small business financing relates to broader economic benefits, a wealth of governmental and academic studies have repeatedly shown the positive impact - both in terms of job creation as well as economic growth - of Canadian small business (see, for example, Fisher \& Reuber, 2010; Aces, 2006; Statistics Canada, 2009). Going further, however, access to funding at critical stages in a small and young business's life-cycle has been highlighted 
as crucial for future success. In other words, Canadian entrepreneurs are the engine that drives economic growth, and capital is the fuel that makes that engine run.

\section{SUMMARY}

Technology often drives innovation in the financial markets. Traditionally, this innovation has helped large businesses more than it has helped small businesses. Merchant Advances is a technology-enabled financial tool that enables small businesses to access capital that they might not be able to access otherwise. It increases the funding alternatives available to small businesses, which is the main engine of job creation.

\section{AUTHOR INFORMATION}

Dean Drysdale holds an MBA from INSEAD and a Ph.D. in Organizational Behavior from Cass Business School The City University, London. He is a professor of business management at Kwantlen Polytechnic University in British Columbia. His research is focused in the area of entrepreneurial finance. E-mail: dean.drysdale@kwantlen.ca (Corresponding author)

David Gens holds a Bachelor of Commerce (Finance) degree from the University of British Columbia (UBC) where he graduated with honours as a Leslie Wong Fellow. While studying at the University of British Columbia, David was a member of the UBC Portfolio Management Foundation where he and five other students managed a $\$ 4$ million university endowment fund consisting of North American publicly traded fixed income and equity securities. E-mail: david.gens@merchantadvancecap.com

\section{REFERENCES}

1. AdvanceMe Inc. v. RAPIDPAY, LLC, 509 F.Supp.2d 593 (United States District Court, E.D. Texas, Tyler Division August 14, 2007).Aces, Z. J. (2006). How is Entrepreneurship Good for Economic Growth? Innovations, 1(1), 97-107.

2. Audretsch, D. B. (2001). Research Issues Relating to Structure, Competition, and Performance of Small Technology-Based Firms. Small Business Economics, 16(1), 37-51.

3. Berger, A. N., \& Udell, G. F. (1998). The Economics of Small Business Finance: The Role of Private Equity and Debt Markets in the Financial Growth Cycle. Journal of Banking \& Finance, 22, 613-673.

4. Carlsson, B., \& Stankiewicz, R. (1995). On the nature, function and composition of technological systems. In B. Carlsson (Ed.), Technological Systems and Economic Performance: The Case of Factory Automation (pp. 57-87). Dordrecht: Kluwer Academic Publishers.

5. Carrington, C. (2009). Small Business Financing Profiles: Borrowers under the Canada Small Business Financing Program. Ottawa: Government of Canada.

6. Faulkender, M., Flannery, M. J., Hankins, K. W., \& Smith, J. M. (2012). Cash Flows and Leverage Adjustments. Journal of Financial Economics, 103(3), 632-646.

7. Fisher, E., \& Reuber, R. (2010). The State of Entrepreneurship in Canada. Ottawa: Small Business and Tourism Branch - Industry Canada.

8. Gill, A., \& Biger, N. (2012). Factors that Affect Small Business Performance in Canada. International Journal of Entrepreneurial Venturing, 4(2), 1742-5360.

9. Gurbaxani, V., \& Whang, S. (1991). The Impact of Information Systems on Organizations and Markets. Communcations of the ACM, 34(1), 59-73.

10. Industry Canada. (2010, May 14). Comprehensive Review Report (2004-09). Retrieved June 1, 2012, from Canada Small Business Financing Program: http://www.ic.gc.ca/eic/site/csbfp-pfpec.nsf/eng/la03017.html

11. Industry Canada. (2011, July). Key Small Business Statistics - July 2011. Retrieved July 1, 2012, from Small Business Research and Statistics: http://www.ic.gc.ca/eic/site/sbrp-rppe.nsf/eng/rd02608.html

12. Johnson, B. S. (2005, Sep. 6). Patent No. US 6,941,281 B1. United State of America.Korajczyk, R. A., \& Levy, A. (2003). Capital Structure Choice: Macroeconomic Conditions and Financial Constraints. Journal of Financial Economics, 68(1), 75-109.

13. Myers, S. (1977). Determinants of Corporate Borrowing. Journal of Financial Economics, 5, 147-175.

14. Nooteboom, B. (1993). Firm Size Effects on Transaction Costs. Small Business Economics, 5(4), 283-295. 
15. Oliver Wyman. (2010). The Supply of Financing to Canada's Small and Medium-Sized Enterprise Market. Business Development Bank of Canada.

16. Prekumar, G. (2003). A Meta-Analysis of Research on Information Technology Implementation in Small Business. Journal of Organizational Computing and Electronic Commerce, 13(2), 91-121.

17. Sopranzetti, B. J. (1999). Selling Accounts Receivable and the Underinvestment Problem. The Quarterly Review of Economics and Finance, 39(2), 291-301.

18. Statistics Canada. (2009). Survey on Financing of Small and Medium Enterprises. Ottawa: Statistics Canada.

19. Thong, J. Y. (1999). An Integrated Model of Information Systems Adoption in Small Business. Journal of Management Information Systems, 15(4), 187-214.

20. Van Auken, H. E., \& Doran, B. M. (1989). Small Business Capitalization Patterns. The Journal of Applied Business Research, 5(2), 15-22. 
NOTES 